\title{
AC 2012-5324: MONTANA STATE UNIVERSITY'S PERSPECTIVE ON CONSTRUCTION SAFETY AND ITS CULTURAL ASPECTS
}

Prof. Whitney A. Lutey, Montana State University

Whitney A. Lutey, C.P.C., is an Assistant Professor in the Department of Civil Engineering at Montana State University, Bozeman, Mont., where she teaches construction practice, construction estimating, and construction scheduling from the professional practice point of view. Lutey earned her bachelor's of science in construction engineering technology, and minor in industrial and management engineering, Montana State University, 1996, and a master's of construction engineering management from Montana State University in 1997. Primary research included incentive programs for productivity in construction and TQM approaches in small construction firms. Her current research encompasses safety culture, the pedagogy of safety, and ethics in construction practice.

Prof. Penny M. Knoll, Montana State University

(C)American Society for Engineering Education, 2012 


\title{
MONTANA STATE UNIVERSITY'S PRESPECTIVE ON
}

\section{CONSTRUCTION SAFETY AND ITS CULTURAL ASPECTS}

\begin{abstract}
This paper explores the current status of safety in construction as it is approached in our state. The culture of our individualistic state is one that naturally resists rules and regulations, primarily the Occupational Safety and Health Act (OSHA) and state laws. Multiple agencies have formed programs and informative works to help Contractors develop a strong safety culture; however, many of these resources are not effectively engaged. Compared to other states, even those bordering ours, the accident incident rate is twice that of the national average.

The culture of this state will be discussed at length to set the stage for understanding the current safety culture. In order to create a paradigm shift in our students, it is apparent that we also need to better understand their generation. The barrier to changing the safety culture in our state lies within understanding the student's generational culture. By understanding the key drivers of our student's behavior, we can more effectively deliver leadership and safety tools for their implementation.
\end{abstract}

This investigation is a work in progress, first highlighting recently passed laws set to improve the state's safety statistics, where progress will be measured in the next three to five years, and second, proposing pedagogical changes to improve the safety culture of future construction graduates.

Introduction

State History

Montana ranks 44th in population ahead of six other states (Alaska, Wyoming, South Dakota, North Dakota, Vermont and Delaware). In 2010, population was just over 989,000 people yet this is an overall increase in population by $23.8 \%$ since 1990 .

It is a diverse state geographically. The fourth largest state in the United States of America (US), only Alaska, Texas and California out rank it in size. It borders three Canadian provinces to its north and is surrounded by four other states to its east, west and south boundaries. Topographically the state is just as diverse; due to the Continental Divide. The Continental Divide runs northwest to south-central splitting the state into two distinct western and eastern regions. The western region is known for its mountainous areas, most being associated geographically and geologically as part of the Northern Rocky Mountains and accounts for roughly $40 \%$ of the state's land mass. The remaining land mass belongs to the eastern region and is mainly prairie. It is collectively known as the Rocky Mountain Front. 
The state's eastern region was part of the Louisiana Purchase in 1803 and was part of the Lewis and Clark Expedition in 1804 to 1806. With the findings of gold and copper in the late 1850's, Montana became a US Territory on May 26, 1864 and the 41st state on November 8, 1889. Mining and cattle ranching have been the major themes of the state history. Mining has been associated with the state since the late 1850's with the discovery of gold in Bannack Creek (near the capital) and by 1888, had more millionaires per capita than any other city in the world. Cattle ranching has been associated with the state since the late 1800's, mostly due to the Homestead Act of 1862 and its revision in the early 1900's, which expanded the amount of land a settler could claim. With pioneering spirit, looking for fortune or land ownership, settlers came by the thousands. Within a two decade period, the populous had increased by $265 \%$ to 243,000 persons in 1890.

The economic base for the state today is agriculture. In 2010, the per capita personal income was roughly $\$ 23,800$ per year. There are significant industries for timber and mineral extractions, including gold, coal, silver, talc and vermiculite. Tourism also plays a large role today in the state's economy.

The state and its people have that rugged, independent mentality, much like its diverse, rich geographical nature. While the majority of work is in agriculture, mining, and timber, construction type jobs have become more plentiful since the construction boom of 2000. With this boom came people, and with people came the need for more houses, buildings, and jobs. Despite challenges reflected in the recession, within a ten year span (2000 to 2009), an additional 175,000 people arrived and the need for construction safety awareness has become paramount, evident by the data presented below.

Facts about Safety

There is an overwhelming problem with worker's safety in Montana. According to the Department of Labor and Statistics, roughly 50\% more days are lost to injury or illness than the national average. The state is number four in the number of worker fatalities per year in the US ${ }^{1}$ and has the second highest injury rate in the country. This poor safety record costs businesses $\$ 4.60$ per second or $\$ 145$ million annually. ${ }^{2}$ Neighboring states have lower workplace injury rates. Even when an injury occurs, workers have a much more difficult time making the transition back to work. Injured workers stay out of work an average of 23 days longer than workers in the rest of the country. ${ }^{2}$

These sobering statistics are not limited to what some would argue as a dangerous industry, such as mining, agriculture, and timber. In reality, there is not one industry that has a significantly higher rate of injury or illness than others. Across the board, from health care to retail, the state has a very poor safety record.

\section{Key Statistics}

In 2009, there were 17,200 nonfatal occupational injuries and illnesses of employees. This produced an overall incidence rate of 5.3 accidents and illnesses per 100 full-time workers which was a decrease from 2007 and 2006's data which averaged 6.3 and 6.9 injuries and illnesses 
respectively per 100 full-time workers. The national overall incidence rate was 3.6 injuries and illnesses per 100 full-time workers in 2009. ${ }^{3,21}$ Good producing industries such as agriculture, construction, and manufacturing have a higher incidence rate of occupational injuries and illnesses than service providing industries for 2009. Construction had a 7.8 incident rate per 100 FTE employees while the US average for construction was only 4.3 per 100 FTE employees for 2009. Those numbers were down considerably from 2007 rates of 9.8 (MT) and 5.4 (national) per 100 FTE employees. Lost workday cases involve days away from work, days of restricted activity, or both. An estimated 6,800 of the 17,200 cases (39.5 percent) were recordable injuries in 2009 with 5,000 (29 percent) involving at least one day away from work. In 2009, occupational injuries by age were highest in the age group 45 to 54 years with 1,220 injuries reported. There is a steady increase in injuries as workers age, plateauing at 45 to 54 . From the ages 55 to older, there is a decline in the number of injuries. ${ }^{21}$

Construction ranked third out of fifteen industries recorded by the 2009 Montana Occupational Injuries and Illnesses Report with a total of 1,600 injuries and illnesses. For the entire state there were 14,300 recordable injuries. The most commonly reported injuries (44 percent) were sprains and strains. Fractures made up the second leading injury at 8.8 percent of injuries and illnesses reported. Lacerations, punctures, and cuts made up 8.4 percent. $^{21}$

The most devastating issue associated with occupational safety is the loss of life on a job. In 2009, 50 job-related fatalities occurred, with ten coming from the construction industry. ${ }^{20}$ To make matters worse, the state has recorded a steady rate of job-related fatalities. Fatal injuries are highest in the natural resource/mining and agricultural industries each with 15 of the 50 fatalities in 2009. The construction industry had 10 fatalities in 2009; 5 in 2008; 10 in 2007; 6 in 2006; 7 in 2005; 4 in 2004 and 3 in 2003; 6 in 2002; zero in 2001 and 7 in 2000. The age distribution for occupational fatalities in 2009 was highest for the age group 55 to 64 . There were 12 fatalities in that group. ${ }^{20}$

Our state's culture is that people work hard; they work through injury or strain. Based on the harsh reality of living in a rural state, a strong work ethic is instilled. Work is done to completion and people are grateful for employment. With the current economy, fear of job loss is another driver for relaxed attitudes towards safety, when the work must be completed.

What is Being Done with the Construction Industry and its Safety Record There are a surprising number of government and private resources available to make safety better. However, these programs are all relatively recent, underscoring the lack of attention safety has garnered throughout the state's history. Only the Montana Safety Culture Act of 1993 has been around nearly two decades. These programs offer a variety of resources from forums for open discussions on improving safety, to clear structured systems that can be used to implement safety programs and Stay at Work/ Return to Work (SAW/RTW) programs. They all address safety from the same perspective and offer very similar resources to improve safety. These programs include the Montana Safety Culture Act of 1993; WorkSafeMT; several new legislative bills from 2009 and Montana Workers' Compensation System. 
The long history of poor safety in Montana has not been overlooked throughout the years. In 1993, the legislature passed the Montana Safety Culture Act (MSCA) in order to "encourage workers and employers to come together to create and implement a workplace safety philosophy." The act focuses on meeting the needs of each unique workplace by placing the responsibility of designing and implementing safety programs on employers. Therefore, the ultimate goal is to create a safe work environment for all residents by establishing a safety culture within each organization. The MSCA provides resources to organizations seeking compliance with the safety culture act and educates organizations on how to lower costs and improve morale and productivity of employees.

\section{WorkSafeMT}

Formed by the Governor appointed Labor-Management Advisory Council (LMAC) at the end of 2005, WorkSafeMT "addresses two major impact areas for workers in Montana: the high frequency of workplace injuries and the long durations before return to work after an injury.",6 Made up of employers, employees, providers, and other stakeholders, WorkSafeMT is working to develop workplace health and safety as an expectation, not an exception in the state. WorkSafeMT provides "proactive training, education, utilization of available resources, and shared accountability," in order to eliminate occupational death, injury, and illness. ${ }^{6}$ The vision behind WorkSafeMT is to provide the resources and education to employees and employer so that safe work practices are used to prevent injury, illness, and death. The organization envisions health and safety as a primary focus for all employers and employees. WorkSafeMT is using the combination of broadcasting, social marketing, new and innovative programs as well as mature yet almost unnoticed legislation to pass on the value and importance of safety.

2009 Legislation

Several key pieces of legislation were passed into law during the 2009 legislative session. It is a very important step in the right direction that the state law is moving to better address safety.

House Bill 138. Revise employment safety and occupational health acts.

- Revises the Montana Safety Act and the Occupational Health Act to reflect the enactment of Occupational Safety and Health Administration (OSHA) in 1970. Modernizes archaic language in the Act and the Department of Labor may provide onsite safety services to private sector employers that request on-site safety consultation services.

Senate Bill 192. Small business workers' compensation relief.

- The bill allows the establishment by Montana State Fund (MSF) of one or more groups of policy holders for shared risk safety groups where they may share a return on premium if group performance is better than average.

- To be eligible, a policyholder must have a written safety program in place for more than one year, adopt a transitional and return to work program, have at least 3 years of experience without losses, use available safety consultation services from Montana 
State Fund or the Department of Labor, and comply with the terms and conditions established by MSF.

Senate Joint Resolution 30. Study workers' compensation.

- Provides for an interim committee to study workers' compensation cost drivers to include frequency of claims, medical costs, exemptions, presumptive diseases, and attorney fees.

- Review the three-tiered system involving self-insurers, private carriers, and the Montana State Fund.

- Examine the operation and structure, relationship with state government and other insurers, and state oversight of Montana State Fund.

- Final results and draft legislation reported to the 2011 legislature.

Montana Workers' Compensation System

Montana workers' compensation system strives to "provide, without regard to fault, wage-loss and medical benefits to a worker suffering from a work-related injury or disease." 6 The workers' compensation system works to compensate workers with reasonable compensation reflecting actual wages lost, with reasonable cost to employers.

\section{Student Generational Culture}

The barrier to changing the safety culture in our state lies within understanding the student's generational culture. The millennium generation is stigmatized as a self-centered, indulgent, arrogant population. Ironically, recent research reveals that their concerns and goals mirror those of the baby boomer generation. ${ }^{7}$

By understanding the key drivers of our student's behavior, we can more effectively deliver leadership and safety tools for their implementation. The ultimate goal: training future industry leaders who take Montana out of this safety slump. Along their career path each student will have the opportunity to influence others and improve the safety culture of Montana.

We begin by addressing the current millennial student, born between 1979 and $1994 .^{7}$ Thielfoldt $\&$ Scheef advise that millennials are primarily team-oriented and prefer to work in groups over individual work. "A new generation is forcing change and the character of that change is student - focused and based on collaboration." "While they do perform and work hard, the student requires structure by means of step-by-step goals along with the information and resources required to complete their tasks. "They appreciate structure and stability," and therefore mentoring and teaching, "Should be more formal," and although confident and intelligent, they seek and, "respond well to ...personal attention.",

On one hand the exceptionally vocal, entitled millennial can be viewed as a challenge simply due to the fact they do not fit the mold of previous student populations. While on the other hand, they are technologically savvy, entrepreneurial, active, worldly, competitive, and visionary. ${ }^{9}$ One opinion extolled, "young people at school... use technologies in ways that are related to their purposes and exhibit a diversity that contrasts with the idea of a sharp generational change... 
these changes are mediated by the active appropriation of technology by young people who act purposively and in relation to influential institutional contexts." ${ }^{10}$ And they have sincere values of diversity, sustainability, social responsibility, and accountability. "Learning styles and expectations of this group are very different from earlier generations. [And instructors] ... need to utilize the latest technology to deliver audio-visually rich, multi-tasking challenges which require a collaborative approach, offer instant feedback whilst at the same time recognizing that its participants may not see the need for or indeed take responsibility for their own development or its perceived failings." 11 More than one author pointed out that, "cooperative teaching techniques have improved content learning, student achievement, and student self-esteem, which may explain why current students are comfortable collaborating on assignments." ${ }^{12}$ Working in a group promotes learning amongst the students, learning from one another, and is less threatening of a task for students who may not perform when working alone.

When we look at the capacity of the student," retaining $10 \%$ of read material, but 20 to $30 \%$ of what is seen," 12 we move from the verbal learner to a more visual learner. In addition, "documents that are text-based are not as popular as documents rich in images, including screen shots and step-by-step instructions." "12 The focus of the student is primarily visual, and to cater to this learning style may provide better outcomes in the classroom.

As a future skill, time management is a challenge for the millennial. They require coaching on, "how to handle day-to-day tasks and responsibilities in the midst of daily interruptions." Instruction and training on breaking up, "larger projects into manageable pieces," is necessary along with aid in meeting deadlines and planning their time. They fail to understand the amount of time it may take to accomplish a task and will need definite stipulations or estimations of the expected time frames for work assignments. ${ }^{13}$

Our students want to gain experience rather than taking the time to pay their dues on the jobsite. This puts forth a challenging teaching opportunity: instructors need to create lessons with instantaneous results. And at the same time we must motivate the student desire to lead so that they're willing to work hard and become the boss. ${ }^{9}$

\section{Pedagogy in the Curriculum}

Our construction program has a distinct beginning and end to incorporate safety in the curriculum. It begins with Construction Practice (ECIV 308), the first course taught in the construction core curriculum and the initial presentation of construction safety to our juniors. The students are taught the history relative to OSHA and the results of the law. Students are instructed on OSHA's fatal facts, along with the Bureau of Labor Statistical data for accidents, injuries, and illnesses in the country, as well as in the state. These basic safety elements are also emphasized in their weekly project site evaluations. The safety assessment provides an opportunity for introspection on whether or not they would feel safe working in the project environments that they observe.

Construction Estimating \& Bidding (ECIV 307) incorporates safety from the means \& methods perspective of how to achieve project completion in the safest manner. The course also 
emphasizes proactive safety budget allocation for proper personal protective equipment and training during construction activities.

The Construction Heavy Equipment class (ECIV 404) lectures start with a Safety Minute where one of the students share a Safety related experience with the class. The majority of the experiences came from an event that the student had participated in or observed on a construction site where they were working. Some of the presentations depict actual injuries they or one of their fellow workers had sustained. Needless to say, the Safety Minutes created a significant impact on the remainder of the class, since this was something one of their peers had encountered and it could conceivably occur on one of their Projects in the future. Most of the presentations were done with PowerPoint slides.

Additionally, all of the lectures related to specific pieces of Heavy Equipment (dozers, loaders, scrapers, etc.) addressed specific, fundamental safety concerns associated with that piece of equipment. The most significant Heavy Equipment safety topic was addressed while Excavators were being studied - an entire lecture (50 minutes) focused on the Safety issues associated with trenching. From a Heavy Equipment perspective, trenching safety is the most abused, and probably the most dangerous use of Heavy Equipment. Crane Safety was also addressed in substantial detail - the current high visibility of crane accidents gaining national attention made this a very timely topic and numerous handouts from ENR and other media sources were provided to the students. Whenever there was a relevant article in the media discussing an accident, a fatality, or other related safety event, the article was provided to the students as a handout and discussed following the opening Safety Minute.

Construction Project Planning \& Scheduling (ECIV 405) incorporates safety from the planning perspective and provides the opportunity in schedule updating and analysis to show how an accident, illness, or injury can create delay on a project. The course stresses safety in the planning aspects of the two class projects, as well as requires students to address the safety of each project's sequenced scheduled activities.

Construction Project Management (ETCC 499R) includes six weeks of intensive safety training in a two-hour lab class setting. Part of the teaching pedagogy in ETCC 499R is to show the students the facts about construction safety. This is done by using the US Department of Labor, Bureau of Labor Statistics, and Occupational Safety and Health Administration data. A separate ETCC 499R safety mid-term was introduced to the class in 2008 to reinforce the idea that construction safety is about human life and that CET students will be responsible for not only their lives but several others whom they supervise. In 2010 a safety final was added to parallel the safety mid-term exam, placing even further emphasis on the mastering of safety standards and laws.

Upon review of similar programs, cited below, we believe that integrating safety into each course is a sufficient measure, rather than creating a standalone safety course. A boon to our program is the faculty's professional background and agreement that like quality, safety belongs in each part of the construction process and therefore belongs in each class. However, incorporating safety into each class could be addressed in a stronger fashion, ensuring accountability of the material, 
which is a challenge for this millennial audience. In addition, safety lessons could be assessed in each course, not only the capstone class.

Review of other curricula

Course emphasis on safety was gathered from land grant universities primarily serving rural locations, similar to the construction program at Montana State University. Those programs that had a distinct safety course are listed together. Although primary focus included ABET accredited universities, these universities are either accredited through the American Council for Construction Education (ACCE) or ABET, Inc., previously known as the Accreditation Board for Engineering and Technology.

- Colorado State University (CSU) - Construction Management Program (ACCE) requires a safety course, MC 317 - Safety Management ( 2 credits) for sophomore students.

- University of Nebraska - Lincoln (UNL) - Construction Engineering Technology Program (ABET) requires a senior level safety course, CET 414 Accident Prevention in Construction (3 credits).

- University of North Texas - Construction Engineering Technology Program (ABET) requires CNET 3410 Occupational Safety and Liability.

- New Jersey Institute of Technology - Construction Engineering Technology Program (ABET) requires CET 323 - Construction Safety.

- California State University Pomona - Construction Engineering Technology Program (ABET) requires ETC 403 Construction Safety.

- North Dakota State University (NDSU)- Construction Engineering Program (ABET) has a safety course, CM\&E 385 - Construction Safety, a two credit course providing an, "introduction to the planning and administration of construction safety programs, including: history and development of federal and state construction safety standards; methods for abatement and control of jobsite hazards to develop safe working environments." 14

- Iowa State University (ISU) - Construction Engineering Program (ABET) does not have a specific safety course.

- Youngstown State University - Civil \& Construction Engineering Technology Program (ABET) does not have a specific safety course.

- Louisiana Tech University -Construction Engineering Technology Program (ABET) does not have a specific safety course.

- University of Toledo - Construction Engineering Technology Program (ABET) does not have a specific safety course.

Conclusion and Recommendations

\section{Best Practices}

Providing a hands-on, interactive classroom experience is what much of the literature review is dictating. Feedback and dialog are also strongly desired by the millennial student. It is not enough to provide homework assignments as interactive learning opportunities. The neediness 
described in Shaw's article shares the challenge of the instructor to provide the feedback (necessary for the student to remain motivated in the classroom) during the lesson.

Taking this into account, pedagogical change could be addressed by modifying safety assignments so that they are highly interactive group projects. Each group requires a project leader, someone who can build consensus. These projects should allow for each student the opportunity to work as the consensus builder and the leader. This way the instructor provides multiple assignments with an outline of control for the group, but they work together for a common goal, each transitioning their role and gaining additional skills. The challenge lies with the number of students in the class and the ability to provide the right level of feedback for each student.

While current technology on the campus of Montana State University includes the use of Desire2Learn, the web enhancement of our courses has supplemented out-of-class work. In these cases, the interactive site allows for course content and assignments to be posted and submitted, discussion opportunities, as well as a location for quizzes and grading feedback. As the site is accessible via an internet connection, students and instructors can access the virtual classroom from remote locations and gather information they need to perform. As a compliment to the classroom safety instruction, safety websites are linked to this course website, where students can access data for specific assignments. This web based tool primarily functions as a compliment to in-class instruction.

This investigation captured two basic ideas; the next generation construction professional in the state of Montana will have the opportunity to lead the industry into safer practices, but in order to do so, that generation must be directed how to find the information they need and be given a direction to proceed. For the benefit of the greater good, may or may not be enough reason to compel the millennials to perform and succeed in refining an untamed Montana.

As far as the benefits of this study and the recently passed laws set to improve the state's safety statistics, the authors believe that progress will be measured in the next three to five years. This study is essentially a work in progress and future verification of results will prove positive with improved safety statistics.

Bibliography

1. Montana Department of Labor and Industry Research and Analysis Bureau. 2007 Incidence Rates Comparison. 2007. Web. http://www.ourfactsyourfuture.org/cgi/databrowsing/?PAGEID=4\&SUBID=183

2. WorkSafeMT. Create a Safety Committee: Empowering employees to create a culture of safety. Web. http://worksafemt.com/index.phpoption=com_content\&view=article \&id=98:safetycommittee \&catid=66\&It emid $=77$

3. Montana Department of Labor and Industry Research and Analysis Bureau. Montana Occupational Injuries and Illnesses 2007. Web. http://www.ourfactsyourfuture.org/admin/uploadedPublications3735_OSH07Report.pdf

4. Montana Department of Labor and Industry. Labor-Management Advisory Council on Workers'

Compensation. 2005. Web. http://erd.dli.mt.gov/annualrpt/ar07/Section\%201.pdf 
5. Montana Department of Labor \& Industry Employment Relations Division. Work Place Safety and Health Bureau. Montana Safety Culture Act. Web. http://worksafemt.com/images/stories/PDFs/WSMTMTSafetyBrochure.pdf

6. Montana Department of Labor and Industry Employment Relations Division. Workers' Compensation Annual Report. 2008. Web. http://erd.dli.mt.gov/annualrpt/ar08/annualreport2008.pdf

7. Hewlett, S., Sherbin, L., and Sumberg, K. (2009). How Gen Y and Boomers will Reshape your Agenda. Harvard Business Review, 87.7-8. p.71-76.

8. Thielfoldt, D., and Scheef, D. (2004). Generation X and the Millennials: What you Need to Know about Mentoring the New Generations. Law Practice Today. Web. http://www.abanet.org/lpm/lpt/articles/mgt08044.html\#author

9. Tips for Working with the Generation Y Millennial, Women in Higher Education, 19.1 (Jan 2010): p.2223.

10. Jones, Chris (2010) Editorial: A new generation of learners? The Net Generation and Digital Natives Learning, Media and Technology Vol. 35, No. 4: 365-368.

11. Shaw, Sue and Fairhurst, D. (2008) Engaging a New Generation of Graduates. Education \& Training Vol. 50, Issue 5: $366-378$.

12. Kipnis, Daniel G. and Childs, Gary M.(2004) 'Educating Generation X and Generation Y', Medical Reference Services Quarterly, 23: 4, $25-33$.

13. Martin, Carolyn A. (2005) From High Maintenance to High Productivity What Managers Need to Know about Generation Y. Industrial and Commercial Training. Vol. 37, No. 1: p. 39-44.

14. North Dakota State University. Construction Management and Engineering Course Descriptions. Web. http://www.ndsu.edu/cme/resources/Bulletin\%20Course\%20Descriptions.pdf

15. Montana Code Annotated 2011. Title 39. Labor. Web. http://data.opi.mt.gov/bills/MCA_toc/39.htm

16. Montana Department of Labor \& Industry Employment Relations Division. "New IC Laws Explained." Web. http://erd.dli.mt.gov/wcregs/iclawexplained.asp

17. Montana State Fund. "Our Mission and Vision." Web. http://www.montanastatefund.com

18. Montana State Fund. "What Affects Your Premium." Web. http://www.montanastatefund.com

19. WorkSafeMT. Design a Stay at Work / Return to Work Program: The benefits of getting back on the job. Web. http://www. worksafemt.com/index.phpoption=com content\&view=article\&id=105:design-a-returnto-work-program\&catid=70\&Itemid=77

20. Montana Department of Labor and Industry Research and Analysis Bureau. Montana Census of Fatal Occupational Injuries 2009. Web. http://www.ourfactsyourfuture.org/admin/uploadedPublications/4092_CFOI09Report.pdf

21. Montana Department of Labor and Industry Research and Analysis Bureau. Montana Occupational Injuries and Illnesses 2009. Web. http://www.ourfactsyourfuture.org/admin/uploadedPublications/4531_OSHS09.pdf

22. US Census Bureau. "State \& County Quick Facts." http://quickfacts.census.gov/qfd/states/30000.html 